\title{
High Testosterone Levels and Sensitivity to Acute Stress in Perpetrators of Domestic Violence With Low Cognitive Flexibility and Impairments in Their Emotional Decoding Process: A Preliminary Study
}

\author{
Ángel Romero-Martínez ${ }^{1}$, Marisol Lila ${ }^{2}$, Patricia Sariñana-González ${ }^{1}$, Esperanza González-Bono ${ }^{1}$
} and Luis Moya-Albiol ${ }^{*}$

${ }^{1}$ Psychobiology Department, University of Valencia, Valencia, Spain

${ }^{2}$ Department of Social Psychology, University of Valencia, Valencia, Spain

: : : : : : : : : : : : : : : : : : : : : : : : : : : : : : : : : :

\begin{abstract}
Hormonal and neuropsychological impairment in intimate partner violence (IPV) perpetrators could play a role in domestic violence. For characterizing whether there is a specific psychobiological response to stress, participants who had previously been jailed for IPV and controls were compared for testosterone and cortisol levels, tested for 2D:4D ratio (as an indicator of masculinization), and given several trait questionnaires and neuropsychological tests related to executive functions and theory of mind. After performing the Trier Social Stress Test (TSST), IPV perpetrators experienced decreases in salivary testosterone (T) levels, a moderate worsening of mood, slight anxiety, and a salivary cortisol (C) level increase. Moreover, high basal T was related with high levels of anger and anxiety and worse mood. However, that basal mood does not significantly alter $\mathrm{T}$ levels in response to stress. Nonetheless, controls experienced smaller changes in $\mathrm{T}$ and larger changes in $\mathrm{C}$ and psychological mood. With respect to neuropsychological and cognitive empathic features, IPV perpetrators showed poorer executive performance and emotional recognition than controls. In addition, deficits in both neuropsychological domains were positively associated. Regarding emotional empathy, IPV perpetrators showed higher levels of personal distress than controls. The 2D:4D ratio was lower in IPV perpetrators than in controls. Moreover, only in the former a smaller 2D:4D ratio was related to large increases in $\mathrm{T}$ in response to stress and poor emotional recognition. Together with social aspects involved in IPV, differences in psychobiological variables and their relationships could play a relevant role in the onset and perpetuation of violent behavior. Aggr. Behav. 9999:1-15, 2013. (c) 2013 Wiley Periodicals, Inc.
\end{abstract}

: : : : : : : : : : : : : : : : : : : : : : : : : : : : : : : :

Keywords: acute stress; cognitive flexibility; empathy; intimate partner violence; testosterone

\section{INTRODUCTION}

Between $15 \%$ and $71 \%$ of women from different populations have been victims of physical or sexual violence at some point in their lives (WHO, 2011). Therefore, it is necessary to analyze the aggressors to help eradicate this kind of violence-while also developing prevention mechanisms. Many researchers have studied aggressors and most used a psychological approach, with little interest in the possible influence of biological variables (Pinto et al., 2010). Due to the limited results obtained in psychotherapeutic programs developed for these individuals, it is worthwhile exploring a different approach based on biopsychosocial models (Babcock, Green, \& Robie, 2004) that include psychobiological variables such as hormonal and neuropsychological parameters. This approach enables the wider acknowledgment of intimate partner violence as a complex phenomenon.
One of the most analyzed hormones in violent males is testosterone (T) (Archer, 2006) as an indicator of the

Contract grant sponsor: Spanish Ministry of Health, Social Services and Equality; contract grant number: 2012/001; contract grant sponsor: Ministry of Economy and Competitiveness; contract grant number: PSI2011-25434; contract grant sponsor: Committee for Business, Research and Science of the Regional Government of Valencia; contract grant number: PROMETEO/2011/048; contract grant sponsor: University of Valencia; contract grant number: UV-INV-AE11-40217.

Conflicts of interest: None.

${ }^{*}$ Correspondence to: Luis Moya-Albiol, Faculty of Psychology, Psychobiology Department, University of València, Avenue Blasco Ibañez, 21 46010 Valencia, Spain. E-mail: luis.moya@uv.es

Received 4 May 2012; Accepted 12 April 2013

DOI: $10.1002 / \mathrm{ab} .21490$

Published online XX Month Year in Wiley Online Library (wileyonlinelibrary.com). 
activity of the hypothalamic-pituitary-gonadal axis (HPG). Some violent males, including rapists, alcoholic aggressors, and anti-social personality disorder (ASD) criminals, show higher basal T levels: but the results are not unanimous (Moya-Albiol, 2010). The studies mentioned used the basal $\mathrm{T}$ levels as a feature factor, due to their high temporal stability (Liening, Stanton, Saini, \& Schultheiss, 2010). Nevertheless, in the same way as with every hormone, there are fluctuations in levels related to diverse causes, such as behavior or the environment - and oscillations may be related to mood swings (Liening \& Josephs, 2010). Additionally, modifications in T levels may produce mood changes. In this sense, $\mathrm{T}$ replacement treatments increase anger, hostility, and/or irritability (van Honk \& Schutter, 2007).

The mechanism behind the relationship between $\mathrm{T}$ and violent behavior is not totally determined. Nevertheless, modulatory functions for this hormone have been conferred in interaction with alcohol or drug use (Soler, Vinayak, \& Quadagno, 2000). These include empathy, neuropsychological skills (Pinto et al., 2010), experience, environmental interaction, and/or cortisol (C) levels (Moya-Albiol, 2010). Indeed, C may work as a modulator of the effect of T on behavior (Terburg, Morgan, \& vanHonk, 2009) because $\mathrm{T}$ is closely linked to aggressive behavior only in those participants with low C (Popma et al., 2007).

The interaction between hormonal parameters is established as part of a complex system in which neurocognitive factors must be considered. There may be some deficits whose interaction with hormonal parameters such as $\mathrm{T}$ may either facilitate or inhibit violent behavior. When comparing IPV perpetrators with nonviolent males, the IPV perpetrator group was more likely to misidentify signals given by their partners and react in a hostile and/or violent manner (Babcock, Green, \& Webb, 2008). These detection errors were restricted to neutral and dislike facial expressions that were usually interpreted as hostile signals. Errors decoding facial expressions (which constitute an initial stage of social information processing) may produce deficits in the "theory of mind" (ToM). For this reason, hostile biases in the decoding process, especially in partners, may make it difficult to understand a partner's perspective or feelings (Babcock et al., 2008) and may lead to social inadequacy and even cause the adoption of inappropriate behavior that predisposes violent action (Tirapu-Ustárroz, PérezSayes, Erekatxo-Bilbao, \& Pelegrín-Valero, 2007). The ToM is similar to the concept of "cognitive empathy," although empathy is a multi-dimensional construct which also has an affective component that can be analyzed with two scales of the interpersonal reactivity index (IRI). One of these scales assesses feelings of sympathy for the misfortune of others (empathy or concern), and the other scale measures interior feelings of unease and discomfort in reaction to the emotions of others (personal distress). Additionally, using the IRI, four types of aggressors were obtained, reflecting reductions in cognitive and/or affective empathy capacities (Covell, Huss, \& Langhinrichsen-Rohling, 2007). As shown in several neuropsychiatric disorders such as alexithymia, schizophrenia, and Asperger syndrome, deficits in cognitive empathy and/or ToM may be related to greater difficulties in dealing with emotional and negative interpersonal situations. For this reason, IPV perpetrators may experience higher levels of personal distress because they may misunderstand how they are evaluated by others (Moriguchi et al., 2007; Rogers, Dziobek, Hassenstab, Wolf, \& Convit, 2007; Smith et al., 2012). Psychopathic traits are positively related to perspectivetaking or ToM; and inversely related to affective empathy (Mullins-Nelson, Salekin, \& Leistico, 2006). T may have activator effects in the cognitive-affective system because high levels hinder emotional facial recognition (van Honk \& Schutter, 2007). So when added to an emotional recognition deficit, increases in T may notably reduce the capacity to detect and/or misinterpret affective stimuli.

Diverse neuropsychological functions also show certain diminished levels in males charged with domestic violence. The affection lies in the executive functions, attention, and verbal abilities (Teichner, Golden, Van Hasselt, \& Peterson, 2001). As far as we are aware, the relationship between these deficits and the $\mathrm{T}$ levels of men charged with domestic violence has not been analyzed. These deficits seem to be related with deficits observed in patients with prefrontal cortex (PFC) damage - revealing in many cases a high level of irritability and/or physical aggressiveness (Farmer \& Aman, 2011). However, there is not a solid indication that enables a statement to be made about cerebral damage in aggressors in terms of PFC.

High levels of prenatal androgens may be associated with an excessive masculinization of the central nervous system (CNS). Masculinization has a relatively stable anthropometric indicator throughout life which is the ratio between the length of the index finger and the ring finger, or the 2D:4D ratio (Manning \& Bundred, 2000). Smaller ratios imply a higher prenatal masculinization (Manning, Baron-Cohen, Wheelwright, \& Sanders, 2001) that has been linked to male physical aggression (Bailey \& Hurd, 2005).

As far as we know, no studies have analyzed the hormonal response to a laboratory stressor in adult males charged with domestic violence. In other studies, a conflictive marital discussion was employed as a stressor, but only psychophysiological variables were analyzed (Pinto et al., 2010). Stress response might be elicited in a 
laboratory through various tools, such as the trier social stress test (TSST), which simulates a highly stressful evaluation scenario (Kirschbaum, Pirke, \& Hellhammer, 1993). Studies about the affect under endocrine parameters focused on non-aggressive males in whom $\mathrm{C}$ levels increase while $\mathrm{T}$ levels decrease - and mood worsens (Wolf, 2011).

The main aim of this paper is to confirm whether men charged with domestic violence show specific features that differentiate them from the general population, using several hormonal, cognitive-affective, and neuropsychological parameters that stress the $\mathrm{T}$ response. For this purpose, we assume an integrated psychobiological view that is in consonance with the works we are carrying out in our laboratory (De Andrés-García et al., 2011; GonzálezBono, De Andrés-García, \& Moya-Albiol, 2011; MoyaAlbiol et al., in press). We analyzed the relationship between hormonal and psychological responses to the laboratory stressor using psychological and neuropsychological variables - focusing on $\mathrm{T}$ and its possible relationship with psychological response and the feature variables. We hypothesized that IPV perpetrators would show higher basal T levels (Soler et al., 2000) and lower C levels (Moya-Albiol, 2010) than controls. IPV perpetrators would also present cognitive dysfunctions such as poor cognitive flexibility (Teichner et al., 2001) and poor recognition of emotions or thoughts (Holtzworth-Munroe \& Smutzler, 1996), especially for neutral expressions (Babcock et al., 2008). Finally, we hypothesized that IPV perpetrators should report lower affective empathy (Covell et al., 2007) and a masculinized or smaller 2D:4D ratio (Bailey \& Hurd, 2005). The 2D:4D ratio could explain the high levels of sensitivity to $\mathrm{T}$ effects (van Honk et al., 2011) and may predict $\mathrm{T}$ changes, especially in IPV perpetrators. As supported in a previous study, heightened feelings of anger are related to high $\mathrm{T}$ levels (Herrero, Gadea, Rodríguez-Alarcón, Espert, \& Salvador, 2010). For this reason, we expect that in both groups anger feelings will be related with high $\mathrm{T}$ levelsalthough this relationship could be stronger in IPV perpetrators than controls due to their violent past. Additionally, for the reversal relationship between T and $\mathrm{C}$ and its effects on the neuropsychological and empathic performance, we hypothesized that the neuropsychological performance (Wisconsin card sorting test [WCST]) would be positively related with $\mathrm{T}$ levels (Muller, Aleman, de Haan, \& van der Schouw, 2005) and negatively related to C levels (Egeland et al., 2005). Moreover, emotional recognition (reading the mind in the eyes) will be negatively related to T levels (van Honk \& Schutter, 2007) and positively related to C levels (Smeets, Dziobeck, \& Wolf, 2009). The analysis of these variables and their relationships may offer a wider explanation of the complex phenomenon of domestic violence, and may delimit differences between categories of IPV perpetrators.

\section{METHODS}

\section{Participants}

The final sample was composed of 40 healthy men (19 IPV perpetrators and 21 controls) who participated voluntarily in the study. IPV perpetrators were recruited from the community and the psychoeducational treatment program CONTEXTO at the University of Valencia in Spain where they were serving as mandatory participants in male abuser programs at the Department of Social Psychology of the University of Valencia (Lila, Oliver, Galiana, \& Gracia, 2013). The selection criteria and assessment of candidates have been described in detail previously (Romero-Martínez, González-Bono, Lila, \& Moya-Albiol, 2013). The average age of the participants was $37.55 \pm 1.67$ years old; and body mass index (BMI) $27.37 \pm 0.55 \mathrm{~kg} / \mathrm{m}^{2}$. The inclusion criteria for controls included: having no organic or mental illnesses, and having similar anthropometrical and demographic characteristics to the IPV perpetrators; as well as not having perpetrated severe violence (defined as assaulting a partner or other individual outside the home, or engaging in any severely violent act). Control individuals were required to provide criminal record certificates to check that they had no history of violence. Further, all participants were interviewed by trained researchers (with extensive experience treating IPV perpetrators) to assess their mental health. Cohen's kappa, used to assess inter-rater agreement between qualitative interviewers in the nine psychopathological dimensions evaluated (the same dimensions as the SCL90-R), ranged from .67 to .84. Regardless of the objective SCL-90-R results, subjects were considered not to have any psychopathological signs and symptoms if they scored less than the mean for their age for each dimension. Candidates were eligible to participate if the qualitative interviews and SCL-90-R scores confirmed they were free of mental illness; three IPV perpetrators and four controls were excluded because their results suggested psychological disorders. All participants were right-handed and healthy, lived in Valencia (Spain), and gave written informed consent. The experiment was performed in accordance with the Helsinki Declaration and approved by the University of Valencia Ethics Committee.

\section{Procedure}

Each subject participated in three sessions that were carried out at the psychobiology laboratories at the University of Valencia. In the first session participants were interviewed in order to identify (and subsequently 
reject) participants who suffered from organic or psychological diseases. The second session took place between $4 \mathrm{pm}$ and $7 \mathrm{pm}$ in order to control diurnal variations of C secretion (Dickmeis, 2009). Participants were instructed to abstain from eating or brushing their teeth, as well as caffeine, alcohol, or exercise, and any drug $2 \mathrm{hr}$ before arriving at the laboratory. All participants were informed about the fact that they would provide saliva for hormonal analyses, and that they would be asked to perform several behavioral tasks. After arriving at the laboratory participants were conducted to a room where they signed an informed consent to participate in the study, and anthropometrical (height, weight, and 2D:4D digit ratio) and substance consumption variables (tobacco, drug, alcohol abuse, and medication) were registered. Before stress exposure started, two saliva samples for evaluating $\mathrm{C}$ and $\mathrm{T}$ levels and three questionnaires for measuring psychological states (STAI-T, STAXI, and POMS) were completed. Participants were then conducted to another noiseinsulated room with a constant temperature $22 \pm 1^{\circ} \mathrm{C}$ where they carried out an adapted version of the TSST (Kudielka, Buske-Kirschbaum, Hellhammer, \& Kirschbaum, 2004). The TSST is a standardized psychosocial laboratory stressor that consists of preparing a speech about a specific argument during a brief preparation period followed by a test period in which participants deliver a specific argument and then perform mental arithmetic tasks. In these cases, all participants had to express their opinion about IPV during $2.5 \mathrm{~min}-$ and interviewers asked a set of related questions during the final minutes of the participant's presentation. Participants then performed an arithmetic task consisting of subtracting numbers in a constant series, or calculating simple arithmetical operations such as additions, subtractions, multiplications, and divisions. To increase the evaluative threat perception, four evaluators of both genders carried out the TSST and a video camera was connected during the test (false registration). The whole procedure included the following periods: baseline, preparation, anticipatory, task and post-task; and all the periods lasted $15 \mathrm{~min}$. Between public speaking task instructions and the preparation period, two saliva samples were taken. Furthermore, when the stressor finished, four saliva samples were collected $(+0,+15$, +30 , and $+45 \mathrm{~min})$. A second psychological state measurement was obtained after the psychosocial stressor, and researchers evaluated the performance appraisal, perceived stress, and internal and external attribution. The third laboratory session took place 1 day after the previous session, and between 10 am and $2 \mathrm{pm}$ to avoid a fatigue effect due to the working day. In this session, two neuropsychological tests were administrated, the WCST and the reading the mind in the eyes (eyes test).
Finally, participants completed a battery of questionnaires for evaluating psychological trait profiles. Data of $\mathrm{C}$ for two IPV perpetrators was not determined due to insufficient saliva volume (not enough salivation). Moreover, three participants reported personal problems (one IPV and two controls) and could not complete the eyes test and the WCST.

\section{Appraisal and State Self-Reports}

After the TSST, four questions were assessed to evaluate task appraisal using a list of four items based on previous studies (Baggett, Saab, \& Carver, 1996; Carrillo et al., 2001; Moya-Albiol et al., in press). The first question refers to satisfaction with performance in the test. The second concerns self-appraised performance, and the third evaluated internal (e.g., personal effort and physical and technical abilities) and external (e.g., luck) attribution of the outcome. The final question measured the degree of stress perceived during the TSST. All of these questions were answered using a 10-point Likerttype scale.

State anxiety was assessed using the "State-Trait Anxiety Inventory" (STAI-S) (Spielberger, Gorusch, Lushene, Vagg, \& Jacobs, 1983) suitably adapted, which contains 20 items, ranked on a 4-point Likert scale. The reliability coefficient was 0.62 .

A Spanish version of the "State-Trait Anger Expression Inventory-2" (STAXI-2) (Miguel-Tobal, Casado, Cano-Vindel, \& Spielberger, 2001) was employed for measuring state anger. It contained 15 items ranked on a 4-point Likert scale and distributed into three subscales: feelings, verbal, and physical expression. To reduce the number of tests, increase power for effect size, and aid interpretation within a conceptual framework, state anger subscales were combined into the single variable (S-Ang). Cronbach's alpha ranged from 0.67 to 0.89 .

Mood states were measured using the abbreviated version of the profile of mood states (POMS) suitably validated (Fuentes, Balaguer, Meliá, \& García-Merita, 1995). This questionnaire is composed of 29 Likert-point items grouped into five subscales (tension, depression, anger, vigor, and fatigue) with a Cronbach's alpha higher than 0.80 . All the scales apart from vigor stated negative mood. A total score was calculated by adding all the negative scales and subtracting vigor (POMS-t).

\section{Psychological Trait Profiles}

The interpersonal reactivity index (IRI) assesses four aspects of empathic response (Davis, 1983). We used the Spanish adaptation (Mestre, Frías, \& Samper, 2004), which includes four subscales (perspective taking, fantasy, empathic concern, and personal distress) ranked in a 5-point Likert scale with reliability coefficients ranging from 0.56 to 0.70 . 
Anger and its expression was measured by an adapted version (Miguel-Tobal et al., 2001) of the State-Trait Anger Expression Inventory-2 (STAXI-2) (Spielberger et al., 1983). This test is distributed into six subscales: two for evaluating trait anger (temperament and reaction) and four for anger expression (anger expression out, anger expression in, anger control out, and anger control in). To reduce the number of tests, increase power for effect size, and aid interpretation within a conceptual framework, trait anger subscales were combined into a single variable (T-Ang). Moreover, a general anger expression index (AEI) is calculated by adding the scores of the two expression subscales and subtracting the scores of the two control scales, and finally adding 36 units to avoid negative scores. The Cronbach's alpha ranged from 0.67 to 0.89 .

\section{Neuropsychological Measures}

The revised version of reading the mind in the eyes (eyes test) was administered. This task is considered an advanced theory of mind test that contains 36 black and white photographs of the eye region of the face of different actors and actresses. Subjects must attribute the mental state of the actors. Participants were instructed to choose which of four words best described what the person in the photo was thinking or feeling. Scores are calculated as the total number of correct choices for all 36 photographs (Baron-Cohen, Wheelwright, Hill, Raste, \& Plumb, 2001).

The revised version of the WCST (Heaton, 1993) was used to measure cognitive flexibility. Cards must be sorted until six categories are matched or until all 128 cards are sorted. Cards are matched according to different criteria such as color, form, and number. After 10 consecutive correct cards are sorted, a new criterion is instituted without warning.

\section{D:4D Digit Ratio}

The 2D:4D ratio was obtained by taking photocopies of the palms and fingers of both hands and measuring the length of the second to the fourth digit from the most proximal wrinkle in each finger to the tip-using a calliper for this purpose. The ratio was calculated by dividing the length of the second by the fourth digit (Manning et al., 2001).

\section{Hormonal Determination}

Saliva was directly collected from the mouth to a glass tube for $\mathrm{T}$ determination using a salivette (Sarstedt, Rommersdolf, Germany) for C. All saliva samples were collected in the same order: firstly $\mathrm{C}$, and then $\mathrm{T}$ immediately afterwards. Participants were informed about the necessity of following the instructions for saliva sampling in order to obtain valuable data. The samples were frozen at $-20^{\circ} \mathrm{C}$ until analyzed by enzimoimmunoassay in the case of $\mathrm{T}$, and radioimmunoassay (RIA) in the case of C.

The salivary $\mathrm{T}(\mathrm{T})$ appropriate reactive was the "saliva T Elisa kit" T (Diagnostics BiochemCanada Inc, Canada, Dorchester, Ontario Canada). Enzimoimmunoassay was used in its determination. The assay sensitivity was $1 \mathrm{pg} /$ $\mathrm{mL}$ and it was expressed in $\mathrm{pmol} / \mathrm{L}$. Good precision was obtained, with intra and inter-assay variation coefficients of $3.98 \%$ and $7.98 \%$, respectively.

Salivary C (C) levels were determined by RIA using an appropriate reactive count-a-count C (DPC-Siemens Medical Solutions Diagnostics, Bad Nauheim, Germany) with $0.5 \mathrm{ng} / \mathrm{dL}$ sensitivity. All samples were analyzed in duplicate and the samples of the same subject were included in the same assay. Although the variation coefficient necessary for replication was fixed at $8 \%$, the maximum intra- and inter-assay variation of the coefficients obtained were $4.3 \%$ and $5.2 \%$, respectively. All the values were expressed in nmol/L.

\section{Data Analysis}

It was previously established using the KolmogorovSmirnov statistic $(p<.001)$ that the data was normally distributed. T-tests were carried out to check significant differences between groups (IPV and control men) in age, BMI, appraisal scores, psychological trait profiles (STAXI-2 and IRI), performance in the neuropsychological test (WCST and eyes test), and in the 2D:4D ratio. Effect sizes for the between-group differences were calculated using Cohen's d (Cohen, 1988). Chi square analyses were performed for alcohol, tobacco, and drugs.

For psychological state responses, repeated-measures ANOVAs with "moment" (pre and post) as the withinsubject factor and "group" as the between-subject factor were performed. To analyze $\mathrm{T}$ and $\mathrm{C}$ responses repeated ANOVAs were applied, with "moment" (at six levels: baseline, preparation period, $0,15,30$, and 45 min after TSST) as a within-subject factor, and "group" (IPV and control) as a between-subject factor. GreenhouseGeisser adjustments for degrees of freedom were employed. Partial eta squared was reported as a measurement for effect size. To control for potential baseline differences in psychological variables, or in the 2D:4D digit ratio, ANCOVAs were carried out using baseline values, psychological traits, as well as drug, and tobacco consumption as covariates to see if there were any differences between the groups. Analysis of the area under the curve (AUC) enabled a quantification of the individual's hormonal response to the stressor to be calculated according to the widely used trapezoid formula (Kirschbaum, Kudielka, Gaab, Schommer, \& Hellhammer, 1999; Pruessner, Kirschbaum, Meinlschmidt, \& Hellhammer, 2003; Stalder, Evans, Hucklebridge, \& 
Clow, 2011). Partial AUC were performed considering only the different times before the final measurement. To achieve this, differences between each of the five hormonal values (preparation period and $0,15,30$, and 45 min after TSST) and the baseline level were added and this resulted in one AUC.

To show possible psychological manifestations of hormonal differences/changes that may be indicative of risk for IPV Pearson or Spearman correlation tests were performed where appropriate to examine relationships between. Moreover, a stepwise regression following the Aiken and West (1991) methodology was used. The interaction effects between the group and the psychological state variables for $\mathrm{T}$ or $\mathrm{C}$ response to stress were tested. We entered T AUC as a dependent variable, in Step 1 we entered group as a covariate, in Step 2 we entered a psychological baseline, and in Step 3 we entered the interaction between both. The same procedure was repeated for T baseline, $\mathrm{C}$ AUC and C baseline.

Data analyses were carried out using SPSS 17.0 software (SPSS ${ }^{\circledR}$ Statistics). Statistical significance was accepted for $p$ values $\leq .05$; whereas a tendency to significance was considered as $p$ values $\leq .08$. Average values in the tables are expressed as mean \pm SEM.

\section{RESULTS}

\section{Participant Characteristics and Psychological Trait Profiles}

Descriptive characteristics and psychological trait profiles for the IPV and controls are presented in Table I. Groups did not differ in age or BMI. The IPV men showed a lower left-hand 2D:4D digit ratio than the controls $(t=-1.93, p<.06, d=.80)$, although these differences were not replicated in the right hand. Differences in tobacco consumption, alcohol, and drug abuse $\left(\chi^{2}(1)=16.85, p<.05 ; \chi^{2}(1)=7.80, p<.01\right.$, and $\chi^{2}(1)=4.91, p<.05$, respectively) were recorded with more IPV than control men using these substances. There were no differences in drug use.

Regarding psychological trait profiles, IPV perpetrators showed lower scores in perspective taking and higher scores in the IRI personal distress scales $(t=-2.10$, $p<.05$ and $t=2.99, p<.01$, respectively) and in anger control in the STAXI-2 subscale $(t=2.15$,

TABLE I. Mean \pm SEM of Descriptive Characteristics, and Psychological Trait Profiles for IPV Perpetrators and Controls

\begin{tabular}{|c|c|c|}
\hline & IPV men $(n=19)$ & Control $(\mathrm{n}=21)$ \\
\hline Age (years) & $38.00 \pm 3.13$ & $35.80 \pm 1.47$ \\
\hline BMI $\left(\mathrm{kg} / \mathrm{m}^{2}\right)$ & $26.97 \pm 0.80$ & $27.55 \pm 0.63$ \\
\hline Left 2D:4D ratio $(\mathrm{t})$ & $0.96 \pm 0.04$ & $0.99 \pm 0.01$ \\
\hline Right 2D:4D ratio & $0.96 \pm 0.03$ & $0.96 \pm 0.04$ \\
\hline \multirow[t]{2}{*}{ Stroke } & Yes $0(0 \%)$ & Yes $0(0 \%)$ \\
\hline & No $19(100 \%)$ & No $21(100 \%)$ \\
\hline \multirow[t]{2}{*}{ Diabetes } & Yes $0(0 \%)$ & Yes $0(0 \%)$ \\
\hline & No $19(100 \%)$ & No $21(100 \%)$ \\
\hline \multirow[t]{2}{*}{ Thyroid illnesses } & Yes $0(0 \%)$ & Yes $0(0 \%)$ \\
\hline & No $19(100 \%)$ & No $21(100 \%)$ \\
\hline \multirow[t]{2}{*}{ Smoker* } & Yes $15(79 \%)$ & Yes $3(14 \%)$ \\
\hline & No $4(21 \%)$ & No $18(86 \%)$ \\
\hline \multirow[t]{2}{*}{ Drug abuse ${ }^{* *}$} & Yes $6(32 \%)$ & Yes $0(0 \%)$ \\
\hline & No $13(68 \%)$ & No $21(100 \%)$ \\
\hline \multirow[t]{2}{*}{ Alcohol abuse* } & Yes $4(21 \%)$ & Yes $0(0 \%)$ \\
\hline & No $15(79 \%)$ & No $21(100 \%)$ \\
\hline Drug & Yes $3(16 \%)$ & Yes $4(19 \%)$ \\
\hline Non-psychiatric & No $16(84 \%)$ & No $17(81 \%)$ \\
\hline \multirow[t]{2}{*}{ Anxiolytic } & Yes $3(16 \%)$ & Yes $0(0 \%)$ \\
\hline & No $16(84 \%)$ & No $0(0 \%)$ \\
\hline STAXI-2 anger expression in & $11.00 \pm 0.70$ & $10.19 \pm 0.47$ \\
\hline STAXI-2 anger expression out & $9.05 \pm 0.54$ & $9.10 \pm 0.48$ \\
\hline STAXI-2 anger control in* & $17.42 \pm 1.06$ & $14.24 \pm 1.03$ \\
\hline STAXI-2 anger control out & $18.37 \pm 0.86$ & $19.48 \pm 0.92$ \\
\hline STAXI-2 AEI & $20.26 \pm 10.00$ & $21.57 \pm 8.01$ \\
\hline STAXI-2 T-Ang & $3.82 \pm 2.09$ & $3.24 \pm 2.27$ \\
\hline IRI perspective taking* & $16.00 \pm 1.00$ & $25.75 \pm 0.76$ \\
\hline IRI empathic concern & $24.21 \pm 0.71$ & $23.05 \pm 0.61$ \\
\hline IRI personal distress** & $16.00 \pm 0.93$ & $12.50 \pm 0.70$ \\
\hline IRI fantasy & $17.58 \pm 0.92$ & $18.35 \pm 0.82$ \\
\hline
\end{tabular}

${ }^{*} p<.05 ;{ }^{* *} p<.01(\mathrm{t}), p<.06$. 
$p<.05)$ than controls, whose effect sizes were 0.78 and 0.79 , respectively.

\section{Neuropsychological Variables}

Data from the eyes test and WCST is presented in Table II. IPV perpetrators obtained a worse performance in the eyes test than the controls $(t=-2.08, p<.05$, $d=0.87$ ). When the eyes test was distributed by gender, IPV perpetrators obtained lower scores in eye recognition $(t=-3.22, p<.01, d=1.04)$, but groups did not differ in recognition of women's eyes. When classified by emotional meaning, IPV perpetrators obtained lower scores in neutral emotions than the controls $(t=-2.31$, $p<.05, d=0.94$ ).

Regarding WCST performance, IPV perpetrators completed fewer categories $(t=-4.92, \quad p<.01$, $d=1.60)$ and committed more total $(t=4.99$, $p<.01, d=1.62)$, perseverative $(t=2.63, p<.01$, $d=0.85)$, percentage of perseverative $(t=2.52$, $p<.01, \quad d=0.82)$ and non-perseverative errors $(t=3.52, p<.01, d=1.14)$ and had lower learn-tolearn scores $(t=-5.10, p<.01, d=1.65)$ than controls. Additionally, IPV perpetrators used more trials than control participants $(t=4.43, p<.01, d=1.44)$.

\section{Stress Responses}

Appraisal scores and psychological state profiles. IPV perpetrators scored similar appraisal scores to controls in satisfaction $(5.01 \pm 1.73$ and $5.78 \pm 1.83$, respectively), internal $(5.41 \pm 1.45$ and $5.47 \pm 2.19$, respectively), and external control index ( $4.58 \pm 1.45$ and $4.52 \pm 2.19$, respectively); but IPV perpetrators perceived the TSST as less stressful than controls $(3.41 \pm 2.49$ and $5.57 \pm 2.38$, respectively; $p \leq .01)$. For this reason, it was covariate in the ulterior analysis.
Basal and post-test psychological state scores are presented in Table III. For anxiety, a significant effect of "moment" and "group $\times$ moment" interaction was found $\left(F(1,38)=22.01, p<.01, \eta_{\mathrm{p}}^{2}=0.37\right) ; F(1$, $\left.38)=10.36, p<.01, \eta_{\mathrm{p}}^{2}=0.21\right)$, respectively). Although both groups increased their states of anxiety after the task, it was lower in the case of IPV perpetrators. No additional effects were obtained after including perceived stress, or tobacco consumption and drugs as covariates.

As in the case of anxiety, the laboratory stressor was shown to be efficient for eliciting mood alterations, since the factor "moment" was significant in tension and anger subscales, as well as in the total score $(F(1,38)=5.41$, $p<.05, \eta_{\mathrm{p}}^{2}=0.13 ; F(1,38)=4.01, p<.05, \eta_{\mathrm{p}}^{2}=$ $0.10 ; F(1,38)=23.99, p<.01, \eta_{\mathrm{p}}^{2}=0.39$, respectively). Additionally a tendency to significance for the vigor subscale was found $\left(F(1,38)=3.28, p<.08, \eta_{\mathrm{p}}^{2}=\right.$ 0.08). All participants experienced worse moods after the task. Moreover, a significant effect for the "group $\times$ moment" interaction was found in the total score $\left(F(1,38)=4.70, p<.05, \eta_{\mathrm{p}}^{2}=0.09\right)$ and a tendency to significance in the anger subscale $(F(1,38)=3.17$, $\left.p<.08, \eta_{\mathrm{p}}^{2}=0.07\right)$. Although both groups increased their scores in anger and total mood after the task, it was lower in the case of IPV perpetrators. The same results were obtained after including the perceived stress or alcohol, drug, and tobacco consumption during the TSST as a covariate, although an additional effect for the "group $\times$ moment" interaction was found in the depression subscale $\left(F(1,38)=4.98, p<.05, \eta_{\mathrm{p}}^{2}=0.12\right)$. In this case, whereas IPV perpetrators decreased depression after the TSST, control participants increased their scores in this subscale.

TABLE II. Mean \pm SEM of Neuropsychological Variables (Eyes Test and WCST)

\begin{tabular}{|c|c|c|}
\hline & IPV men $(n=17)$ & Control men $(n=19)$ \\
\hline Eyes test* & $21.5 \pm 1.37$ & $24.89 \pm 0.88$ \\
\hline Eyes test (men eyes) ${ }^{* *}$ & $10.44 \pm 0.66$ & $13.27 \pm 0.57$ \\
\hline Eyes test (women eyes) & $11.07 \pm 0.92$ & $11.63 \pm 0.49$ \\
\hline Eyes test (positive emotions) & $4.67 \pm 0.36$ & $5.11 \pm 0.45$ \\
\hline Eyes test (negative emotions) & $7.50 \pm 0.82$ & $8.63 \pm 0.39$ \\
\hline Eyes test (neutral emotions)* & $9.33 \pm 0.60$ & $11.16 \pm 0.51$ \\
\hline WCST total trials** & $118.28 \pm 4.45$ & $88.68 \pm 4.08$ \\
\hline WCST correct answer & $70.89 \pm 2.99$ & $70.73 \pm 2.21$ \\
\hline WCST total mistakes ${ }^{* *}$ & $48.00 \pm 5.24$ & $17.89 \pm 2.15$ \\
\hline WCST perseverative mistakes** & $13.78 \pm 4.37$ & $1.95 \pm 0.36$ \\
\hline WCST non-perseverative mistakes** & $34.16 \pm 4.24$ & $16.26 \pm 2.03$ \\
\hline WCST perseverative mistakes $(\%)^{* *}$ & $16.22 \pm 5.79$ & $2.05 \pm 0.47$ \\
\hline WCST failure to maintain set & $1.57 \pm 0.34$ & $0.79 \pm 0.34$ \\
\hline WCST trials to complete the first category & $14.57 \pm 1.81$ & $15.05 \pm 2.17$ \\
\hline WCST number of categories** & $3.56 \pm 0.47$ & $6.00 \pm 0.00$ \\
\hline WCST conceptual level & $7.50 \pm 0.77$ & $6.89 \pm 0.48$ \\
\hline WCST learn to learn ${ }^{* *}$ & $3.22 \pm 0.56$ & $6.00 \pm 0.00$ \\
\hline
\end{tabular}

${ }^{*} p<.05 ;{ }^{* *} p<.01$. 
TABLE III. Mean \pm SEM of Psychological States Before and After Task

\begin{tabular}{|c|c|c|c|c|}
\hline & \multicolumn{2}{|c|}{$\operatorname{IPV}(n=19)$} & \multicolumn{2}{|c|}{ Control $(n=21)$} \\
\hline & Before task & After task & Before task & After task \\
\hline STAI-S* & $18.16 \pm 1.79$ & $19.84 \pm 1.58$ & $14.48 \pm 1.62$ & $23.52 \pm 2.40$ \\
\hline POMS depression & $1.68 \pm 0.71$ & $1.26 \pm 0.53$ & $0.57 \pm 0.32$ & $0.71 \pm 0.29$ \\
\hline POMS tension & $4.95 \pm 0.96$ & $5.42 \pm 0.73$ & $4.57 \pm 0.75$ & $6.48 \pm 0.81$ \\
\hline POMS(t) anger & $1.32 \pm 0.65$ & $1.37 \pm 0.69$ & $0.33 \pm 0.16$ & $1.24 \pm 0.40$ \\
\hline POMS vigor & $13.26 \pm 1.09$ & $12.68 \pm 1.16$ & $13.48 \pm 0.76$ & $12.57 \pm 0.93$ \\
\hline POMS fatigue & $1.37 \pm 0.54$ & $1.37 \pm 0.51$ & $1.38 \pm 0.36$ & $1.62 \pm 0.43$ \\
\hline POMS ${ }^{*}$ total & $-3.94 \pm 2.37$ & $0.68 \pm 1.39$ & $-6.62 \pm 1.39$ & $4.09 \pm 1.09$ \\
\hline STAXI-2** S-Ang & $5.53 \pm 0.17$ & $5.31 \pm 0.69$ & $5.08 \pm 0.18$ & $5.30 \pm 0.54$ \\
\hline
\end{tabular}

${ }^{*} p<.05 ;{ }^{* *} p<.01(\mathrm{t}), p<.06$.

When analyzing anger, a significant effect for the "group $\times$ moment" interaction in the feeling subscale was found $\left(F(1,38)=7.83, p<.01, \eta_{p}^{2}=0.17\right)$ that decreased in IPV perpetrators and increased in controls. Furthermore, the factor "group" proved to be significant in the case of physical expression of anger $(F(1$, $\left.38)=4.05, p<.05, \eta_{\mathrm{p}}^{2}=0.09\right)$, and almost significant in verbal expression $(F(1,38)=3.64, p<.06$, $\left.\eta_{\mathrm{p}}^{2}=0.15\right)$ with IPV perpetrators presenting higher scores in both subscales. No additional effects were obtained after including perceived stress or alcohol, drug, and tobacco consumption as covariates.

Hormonal responses. For $\mathrm{T}$, the laboratory stressor proved to be efficient for eliciting $\mathrm{T}$ changes, since the factor "moment" showed a tendency towards significance $\left(F(2.86,108.59)=2.47, p<.07, \eta_{\mathrm{p}}^{2}=\right.$ $0.06)$. After dividing the sample by groups the factor "moment" was significant for IPV perpetrators and controls $\left(F(2.40,43.26)=2.70, p<.05, \eta_{\mathrm{p}}^{2}=0.13 ; F\right.$ $(3.03,60.60)=2.89, p<.05, \eta_{\mathrm{p}}^{2}=0.13$, respectively). Additionally, a tendency towards significance for the "group $\times$ moment" interaction was found; $F(2.86$, $\left.108.59)=2.55, p<.06, \eta_{\mathrm{p}}^{2}=0.07\right)$. Differences between IPV perpetrators and controls in T baseline values were not found and so there was no reason to include covariates. After including perceived stress during the TSST as a covariate, the interaction reached statistical significance $\left(F(2.83,104.79)=2.68, p<.05, \eta_{\mathrm{p}}^{2}=\right.$ $0.10)$. Post-hoc analyses showed that IPV perpetrators had higher $\mathrm{T}$ levels in speech preparation and post-task periods than controls (for both $p<.05$; Fig. 1). Although groups did not differ in the total T AUC in both partial AUCs (from baseline to anticipatory and from baseline to 0 min after the stressor) significant differences between groups were found when perceived stress was included as a covariate $\left(F(1,40)=5.16, p<.05, \eta_{\mathrm{p}}^{2}=0.12 ; F(1\right.$, $40)=4.16, p<.05, \eta_{\mathrm{p}}^{2}=0.10$, respectively). IPV perpetrators obtained lower T AUC. The same results were obtained after including alcohol, drugs, and tobacco consumption as covariates.
In the $\mathrm{C}$ case, the laboratory stressor proved to be efficient in eliciting $\mathrm{C}$ changes, but only the "moment" was significant in controls $(F(1.56,31.28)=2.65$, $\left.p<.05, \eta_{\mathrm{p}}^{2}=0.12\right)$. No differences were found between groups in $\mathrm{C}$ baseline values and so there was no reason to introduce covariates. No significant effects in the case of $\mathrm{C}$ levels or the C AUCs were found in any case. Although not significantly, IPV perpetrators showed a less pronounced increase in $\mathrm{C}$ levels after the task and until 30 min post-task than the controls (Fig. 2). When C response was analyzed separately, only in the case of controls was there a significant decrease in $\mathrm{C}$ levels between baseline and the preparation period $(F(1$, $\left.20)=11.47, p<.05, \eta_{\mathrm{p}}^{2}=0.29\right)$; while an increase between the preparation period and 15 min post-task was found $\left(F(1,20)=6.97, p<.05, \eta_{\mathrm{p}}^{2}=0.21\right)$. The same results were obtained after including alcohol, drug, and tobacco consumption as covariates.

\section{Relationships Between Variables \\ Relationships between WCST, eyes test, IRI, psychological state scores, and 2D:4D ratio for all participants. The relationships between the variables were summarized in Table IV. In addition, only in the case of IPV perpetrators were the right 2D:4D}

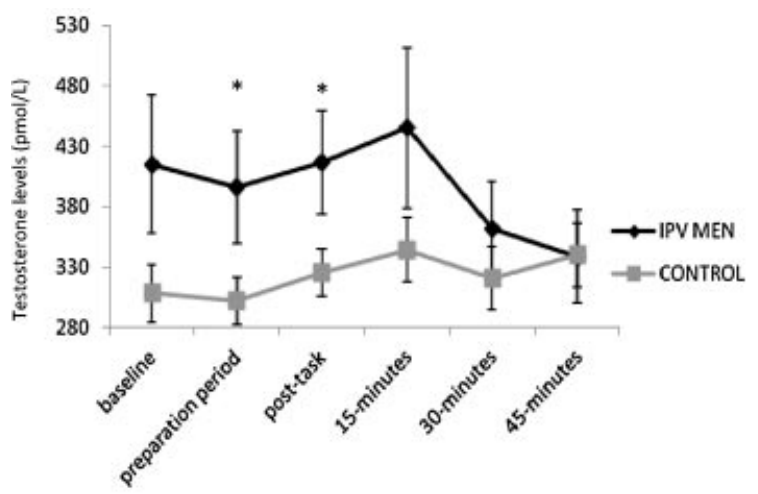

Fig. 1. T levels for IPV perpetrators and control men. 


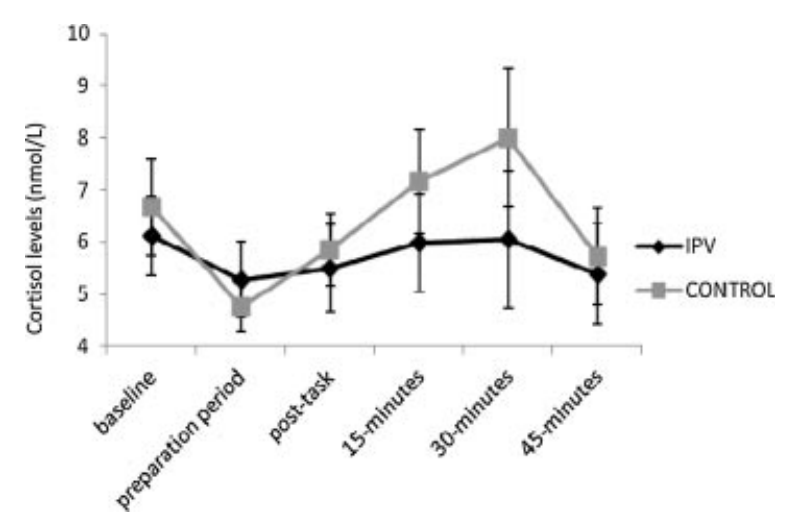

Fig. 2. C levels for IPV perpetrators and control men.

ratios negatively correlated to T AUC $(r=-.521$, $p<.05)$ and positively to the eyes test $(r=.571$, $p<.05)$.

Relationships between WCST, eyes test, IRI and psychological state scores with $T$ and $C$ baseline and AUCs for IPV perpetrators and controls. The relationships between these variables were summarized in Table V for IPV perpetrators and controls.

Thus, significant correlations between these variables were formally tested in hierarchical multiple regressions separately in order to analyze the existence of specific relationships between these variables in both groups. Nonetheless, no significant and specific models for those interactions were found.

Moreover, alcohol, drug, and tobacco consumption included as covariates did not show significant effect on the hierarchical models or predictions.

\section{DISCUSSION}

After presenting the TSST, IPV perpetrators experienced decreases in $\mathrm{T}$ levels, a moderate worsening of mood, slight anxiety, and a $\mathrm{C}$ level increase. Moreover, when basal Twas higher, it was related with high levels of anger and anxiety and worse mood. However, that basal mood does not significantly alter $\mathrm{T}$ levels in response to stress. Furthermore, only in controls high cognitive empathy was associated with a better baseline mood and low anger and anxiety. On the other hand, poor executive performance was related with poor empathic skills. With respect to neuropsychological and cognitive empathic features, IPV perpetrators showed poor executive performance and emotional recognition. For emotional empathy, IPV perpetrators showed higher personal distress than controls. Nonetheless, only in controls better emotional decoding process was related to better cognitive empathy. The 2D:4D ratio was lower in IPV than in controls. In addition, in IPV perpetrators a smaller

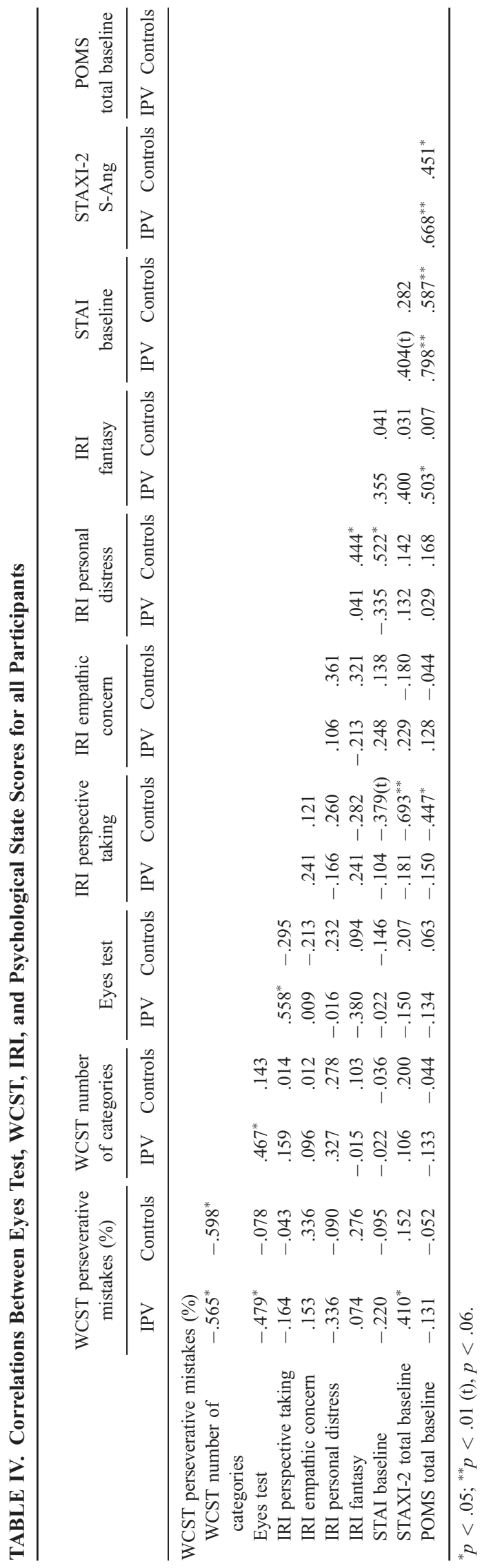




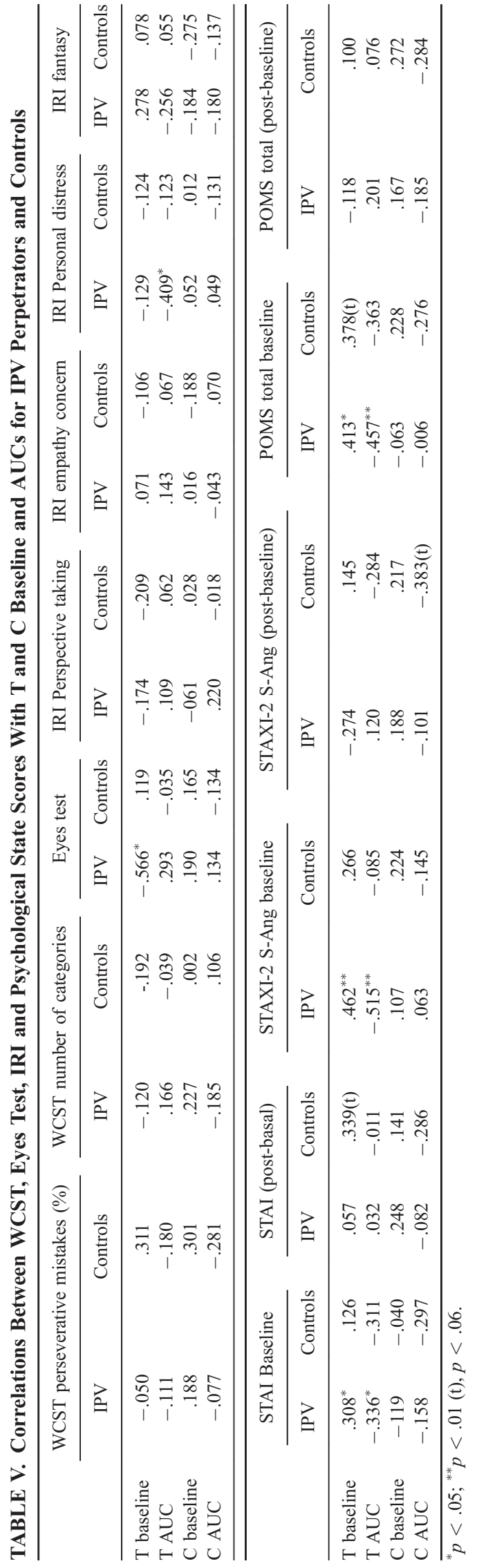

2D:4D ratio was related with large increases in $T$ in response to stress and poor emotional recognition.

The stressor increased anxiety and $\mathrm{C}$ levels, diminished $\mathrm{T}$ levels, and produced a worsening of mood in both IPV and controls. This emphasizes that differences are not due to a different emotionally charged topic of the TSST. In addition, controls experienced more perceived stress than IPV perpetrators and this indicates that they were emotionally involved in the task.

In the general population, the TSST usually induces decreases in $\mathrm{T}$ levels, increases in $\mathrm{C}$ levels and anxiety, and a worsening of mood (Dickerson, Gruenewald, \& Kemedy, 2004; Heinz et al., 2003). However, the relationship between acute psychosocial stress and changes in $\mathrm{T}$ levels has not been frequently studied. This diminution is clear in competitive situations or during physical stress (Schoofs \& Wolf, 2011) but not in other contexts. No studies on this subject have been carried out on IPV perpetrators. In the present test, controls and IPV perpetrators showed these modifications after the TSST.

Our result does not refute the data in the literature that is mainly based on the analysis of baseline T. Those males with higher levels of androgens demonstrated greater increases in anger and aggressive response to threatening stimuli than non-violent men (George et al., 2001; Moya-Albiol, 2010). Moreover, increases in $\mathrm{T}$ levels and in feelings of anger after an exposition to an anger-induction procedure was described in a nonviolent population (Herrero et al., 2010). Although our data does not support $\mathrm{T}$ differences at baseline, IPV perpetrators with high levels of anger and anxiety and worse mood showed high basal $\mathrm{T}$ levels. Thus, when basal Twas higher, a high anger response to stress did not significantly alter $\mathrm{T}$ levels in response to stress. For this reason, IPV perpetrators could perceive the TSST as threatening or hostile in itself. This, in turn, could mean that they adopt a defensive position with smaller $\mathrm{T}$ responses. For that, the negative emotional reactivity of the IPV perpetrators drives most of the differential responding to stress.

Changes in $\mathrm{T}$ levels and the magnitude of response were similar as both groups showed a negative response to acute stress. However, IPV perpetrators experienced greater decreases in their $\mathrm{T}$ levels between the baseline and preparation period than control participants. This result may explain their anticipatory response to psychosocial stress. Moreover, during the preparation period and 0 min after task, IPV perpetrators showed greater $\mathrm{T}$ levels than controls. Therefore, IPV perpetrators and control men may have the same fluctuations in $\mathrm{T}$ levels - but occurring in different ways. Nevertheless, it would be necessary to conduct more studies to assess whether these participants have an abnormal metabolism 
of $\mathrm{T}$ (George et al., 2001), higher $\mathrm{T}$ levels (Soler et al., 2000), or more sensitivity to activation $\mathrm{T}$ effects (Pope et al., 2000). Indeed the 2D:4D ratio could be an indicator of this and so exposure to high $\mathrm{T}$ levels in the womb could increase the sensitivity to androgen in adulthood (van Honk et al., 2011) and facilitate physical aggression in men (Bailey \& Hurd, 2005). In IPV perpetrators, the 2D:4D ratio of the left hand was smaller than controls. For this reason, our results support previous research because the 2D:4D ratio of both hands has been used as index of masculinization (Bull \& Benson, 2006; Romero-Martínez et al. 2013). Therefore, IPV perpetrators may have been exposed to high prenatal $\mathrm{T}$ levels (Manning et al., 2001) and may also present an increased genetic sensitivity (Manning et al., 2003). As described in clinical populations for the case of men with fertility problems, the 2D:4D ratio is related to circulating levels of $\mathrm{T}$ (Manning, Scutt, Wilson, \& LewisJones, 1998). In our study, the 2D:4D ratio predicted substantial changes in $\mathrm{T}$ and poor emotional recognition only in IPV perpetrators - which may reinforce the sensitivity to $\mathrm{T}$.

The TSST produced significant increases in C levels in controls but not in IPV perpetrators. This response is frequent and has been replicated in many populations, which could indicate that IPV perpetrators are less reactive to psychological stress when related to domestic violence. The slight changes in $\mathrm{C}$ levels in IPV perpetrators in comparison with controls may suggest hypoactivity of the HPA axis, which has been associated with aggression and other behavioral problems in violent participants (Gordis, Granger, Susman, \& Trickett, 2006). These results may be explained by a habituation effect (Kudielka et al., 2006) due to the fact that IPV perpetrators reported a low level of perceived stress, anxiety, and a slight worsening of mood. This issue could be the product of repeated exposures to psychosocial stressors during discussions with their partners.

Although it has been suggested that the interaction between high $\mathrm{T}$ and low $\mathrm{C}$ may facilitate aggressive behavior (Carré \& Mehta, 2011), in our study T and C were not directly related. It is therefore important to consider the interactions between hormonal parameters and the cognitive system and how these interactions could predispose to violent behavior (Pinto et al., 2010).

Our data does not support that IPV perpetrators may have a more hostile temperament. Indeed, they tend to describe themselves in interviews and questionnaires in a correct and socially acceptable way (Saunders, 1991). They also describe themselves as people with high levels of external control of anger. In our study, IPV perpetrators showed high levels of control of anger, possibly because their anger reactions are reduced to the domestic domain. In addition, it has been hypothesized that there are different types of offenders according to their empathetic capacities (Covell et al., 2007). The IPV perpetrators analyzed in our study have an impaired capacity to understand the thoughts and emotions of others (cognitive empathy) - but are able to feel compassion for others (emotional empathy). Behind the reduced capacity to understand thoughts and emotions and predict the behavior of others may lay deficits in cognitive components involved in empathy (Tirapu-Ustárroz et al., 2007). Our results lead us to believe that the deficit could be in emotional stimuli decoding, especially in those stimuli with a neutral value. In this sense, a previous study suggested that a significant percentage of IPV perpetrators may have these deficits (Babcock et al., 2008). IPV perpetrators may misunderstand and attribute hostile connotations to neutral stimuli and this increases the likelihood of behaving aggressively (Holtzworth-Munroe \& Smutzler, 1996) if they believe that their partners maligned or blamed them. Our study revealed that IPV perpetrators lacked cognitive empathy but not emotional empathy. However, the eyes test (emotional decoding process) was statistically related to the perspective taking (cognitive empathy) score. That result, although was found only in controls, reinforced the importance of the decoding process for the ToM. As proposed by Covell et al. (2007), this type of IPV perpetrator may feel remorse after perpetrating violent acts. This effect and empathic abilities may be modulated by endogenous $\mathrm{T}$ levels. The administration of exogenous $\mathrm{T}$ in non-violent men produced a higher emotional salience of stimuli associated with such hostility; increasing the probability of displaying anti-social behavior (van Honk \& Schutter, 2007). Rises in endogenous levels resulted in a decrease in empathic abilities (Hermans, Putman, \& van-Honk, 2006). Hence, those results were supported by our results as high $\mathrm{T}$ was related to low empathic abilities. Impairments in empathy were analyzed separately and the relationship with other neuropsychological alterations has not yet been studied. ToM deficits in several diseases such as autism and Asperger syndrome may occur with deficits in executive functions (Baron-Cohen, 2010). Nevertheless, patients with organic frontal lobe damage presented impairments in both functions, and both executive and empathic deficits were relatively independent (Rowel, Bullock, Polkey, \& Morris, 2001) and could coexist without apparent causal connection. However, our results supported the hypotheses that both deficits may be related. Hence, this kind of deficits could difficult the socialization and reintegration processes of IPV perpetrators.

Mental flexibility and/or problem-solving abilities in terms of WCST revealed that IPV perpetrators may have a reduced ability to learn from their mistakes and a certain 
degree of mental rigidity, a result that has already been obtained (Pinto et al., 2010). These potential cognitive characteristics could explain the persistence of sexist stereotypes that frequently appear in IPV perpetrators (Ministry of Interior, Technical General Secretary, 2010). Behind the relationship between worse WCST performance and the increase in physical and verbal hostility may lay impairments in the PFC that are involved in anger and frustration regulation (Koenings et al., 2007). Sexist cognitive schemas combined with potential empathic deficits could constitute an idiosyncratic processing system for ambiguous stimuli that induces violent behavior. However, the activation effects of androgens on cognition should be considered. Decreases in endogenous levels of $\mathrm{T}$ may underlie impairment of several cognitive abilities. Nevertheless, studies analyzing this aspect were conducted in men with symptoms and signs of andropause, and/or endocrine disorders (Beauchet, 2006). To our knowledge, no studies have analyzed this relationship in violent adult men. However, our results did not reveal a direct relationship between $T$ changes and WCST performance. It seems then that the relationship is clearer between $\mathrm{T}$ and empathy and its cognitive processes.

Finally, we must point out that alcohol, cocaine, and marijuana may contribute to the observed differences between groups. A smaller or masculinized 2D:4D ratio, such as that of our IPV perpetrators, could be an indicator of the adoption of reckless behavior, such as alcohol or other drug abuse (Kornhuber et al., 2011). Despite the fact that not all men involved in domestic violence use alcohol or other toxics, a large percentage of men attack their partners under the effects of these substances (Pinto et al., 2010). Alcohol consumption has been linked with both the maintenance and facilitation of domestic violence (Hines \& Douglas, 2011) and could act as an accelerator of violence (Fals-Stewart, 2003); or as a negative reinforcement that mitigates the negative emotions and so entails the perpetuation of violence (Simons, Gaher, Jacobs, Meyer, \& Johnson-Jiménez, 2005) given that the perpetrators analyzed in this study might express remorse after committing a violent act. The current model for this phenomenon goes by the name of the Myopic Model (Steele \& Josephs, 1990) which states that alcoholic intoxication worsens attention capacities and/or information processing. Therefore the quantity of stimuli the subject is able to process decreases and this facilitates a violent reaction (Giancola, Duke, \& Ritz, 2011). This means that other cognitive-affective and neuropsychological factors, in direct or indirect interaction with $\mathrm{T}$, should be considered in order to offer an explanation for domestic violence.

One limitation of the study was the small sample size, and so our study can be considered as a preliminary approach to the analyzed subject. Although the groups differed in several variables such as alcohol, drug, and tobacco consumption, these variables were statistically controlled. Nevertheless, this research was interesting enough to offer some valuable results. Future research may replicate these findings after evaluating a larger sample of IPV perpetrators. Additionally, other variables such as immunity or cardiovascular responses should be included. Our data is relevant and novel as no studies have previously analyzed the psychological and hormonal responses to psychological stress as related to domestic violence in a laboratory context. It would be useful to analyze other subsamples of IPV perpetrators as this would enable a better understanding of a phenomenon as complex as domestic violence.

In conclusion, this study shows that $T$ could be an indirect modulator of aggressive behavior through its effects on the processing of cognitive-affective information. Furthermore, the psychological response might be better explained by cognitive variables than by fluctuations in hormonal levels in IPV perpetrators. Moreover, the negative emotional reactivity of IPV perpetrators drive most of the differential responding to stress. Our data must be considered together with previous reports related to mental health that were assessed qualitatively by trained researchers, the objective reports obtained by SCL-90 scores, and the participants' court records to assess any history of violence. We suggest that endocrine, psychological, and neuropsychological specific biases should be included in the "family-only" (FO) type, as proposed by Holtzworth-Munroe and Stuart (1994), for individuals whose violent behavior is confined to the home. IPV perpetrators normally behave in a nonaggressive way in non-domestic contexts. Babcock et al. (2004) proposed that a biopsychosocial model may increase our knowledge of violent behavior in IPV perpetrators. These results could benefit rehabilitation programs designed for abusers that employ a communitarian and psychotherapeutic perspective focused primarily on changing beliefs, biases, and/or cognitive distortions of offenders. Hormonal parameters and neuropsychological variables indicate the need to use cognitive-affective functions in impaired rehabilitation programs, and even raise the possibility of admission criteria to these programs for participants who may change or learn new behavioral patterns.

\section{REFERENCES}

Aiken, L. S., \& West, S. G. (1991). Multiple regression: Testing and interpreting interactions. Newbury Park, CA: Sage.

Archer, J. (2006). Testosterone and human aggression: an evaluation of the challenge hypothesis. Neuroscience and Biobehavioral Reviews, 30(3), 291-322. doi: 10.1016/j.neubiorev.2004.12.007 
Babcock, J. C., Green, C. E., \& Robie, C. (2004). Does batterers' treatment work? A meta-analytic review of domestic violence treatment. Clinical Psychology Review, 23(8), 1023-1053. doi: 10.1016/j.cpr.2002.07.001

Babcock, J. C., Green, C. E., \& Webb, S. A. (2008). Decoding deficits of different types of batterers during presentation of facial affect slides. Journal of Family Violence, 23, 295-302. doi: 10.1007/s10896-0089151-1

Baggett, H. L., Saab, P. G., \& Carver, C. S. (1996). Appraisal, coping, task performance, and cardiovascular responses during the evaluated speaking task. Personality and Social Psychology Bulletin, 22(5), 483-494. doi: 10.1177/0146167296225006

Bailey, A. A., \& Hurd, P. L. (2005). Finger length ratio (2D:4D) correlates with physical aggression in men but not in women. Biological Psychology, 68, 215-222. doi: 10.1016/j.biopsycho.2004.05.001

Baron-Cohen, S. (2010). Autismo y síndrome de asperger. Madrid: Alianza.

Baron-Cohen, S., Wheelwright, S., Hill, J., Raste, Y., \& Plumb, I. (2001). The "reading the mind in the eyes" Test revised version: A study with normal adults, and adults with Asperger syndrome or high-functioning autism. Journal of Child Psychology and Psychiatry, 42(2), 241-251.

Beauchet, O. (2006). Testosterone and cognitive function: Current clinical evidence of a relationship. European Journal of Endocrinology, 155, 773-781. doi: 10.1530/eje.1.02306

Bull, R., \& Benson, P. J. (2006). Digit ratio (2D:4D) and the spatial representation of magnitude. Hormones and Behavior, 50(2), 194-199. doi: 10.1016/j.yhbeh.2006.02.008

Carré, J. M., \& Mehta, P. H. (2011). Importance of considering testosteronecortisol interactions in predicting human aggression and dominance. Aggressive Behavior, 37(6), 489-491. doi: 10.1002/ab.20407

Carrillo, E., Moya-Albiol, L., González-Bono, E., Salvador, A., Ricarte, J., \& Gómez-Amor, J. (2001). Gender differences in cardiovascular and electrodermal responses to public speaking task: The role of anxiety and mood states. International Journal of Psychophysiology, 42(3), 253-264. doi: 10.1016/S0167-8760(01)00147-7

Cohen, J. (1988). Statistical power analysis for the behavioral sciences (2nd ed.). New Jersey: Lawrence Erlbaum.

Covell, C. N., Huss, M. T., \& Langhinrichsen-Rohling, J. (2007). Empathic deficits among male batterers: A Multidimensional approach. Journal of Family Violence, 22, 165-174. doi: 10.1177/0093854808316218

Davis, M. H. (1983). Measuring individual differences in empathy: Evidence for a multidimensional approach. Journal of Personality and Social Psychology, 44(1), 113-126. doi: 10.1037/0022-3514.44.1.113

De Andrés-García, S., González-Bono, E., Sariñana-González, P., SanchisCalatayud, M. V., Romero-Martínez, A., \& Moya Albiol, L. (2011). Internal attribution of outcome moderates the cortisol response to a cooperative task in women. Psicothema, 23(2), 196-202.

Dickerson, S. S., Gruenewald, T. L., \& Kemedy, M. (2004). When the social self is threatened: Shame, physiology, and health. Journal of Personality, 72, 1191-1216. doi: 10.1177/0146167206290212

Dickmeis, T. (2009). Glucocorticoids and the circadian clock. Journal of Endrocrinology, 200(1), 3-22. doi: 10.1677/JOE-08-0415

Egeland, J., Lund, A., Landrø, N. I., Rund, B. R., Sundet, K., Asbjørnsen, A., Mjellem, N., Roness, A., \& Stordal, K. I. (2005). Cortisol level predicts executive and memory function in depression, symptom level predicts psychomotor speed. Acta Psychiatrica Scandinavica, 112(6), 434-441. doi: 10.1111/j.1600-0447.2005.00599.x

Fals-Stewart, W. (2003). The occurrence of partner physical aggression on days of alcohol consumption: A longitudinal diary study. Journal of Consulting and Clinical Psychology, 71, 41-52. doi: 10.1037/0022006X.71.1.41

Farmer, C. A., \& Aman, M. G. (2011). Aripiprazole for the treatment of irritability associated with autism. Expert Opinion on Pharmacotherapy, 12(4), 635-640. doi: 10.1517/14656566.2011.557661

Fuentes, I., Balaguer, I., Meliá, J. L., \& García-Merita, M. (1995). Forma abreviada del perfil de estado de Ánimo (POMS). Libro de actas del V congreso nacional de psicología de la actividad fisica y el deporte. Valencia: Universidad de Valencia.

George, D. T., Umbau, J. C., Phillips, M. J., Emmela, D., Ragan, P. W., Shoaf, S. E., \& Rawlings, R. R. (2001). Serotonin, testosterone and alcohol in the etiology of domestic violence. Psychiatry Research, 104, 27-37. doi: 10.1016/S0165-1781(01)00292-X

Giancola, P. R., Duke, A. A., \& Ritz, K. Z. (2011). Alcohol, violence, and the alcohol myopia model: Preliminary findings and implications for prevention. Addictive Behaviors, 36, 1019-1022. doi: 10.1016/j. addbeh.2011.05.006

González-Bono, E., De Andrés-García, S., \& Moya-Albiol, L. (2011). The cortisol awakening response in caregivers of schizophrenic offspring shows sensitivity to patient status. Anxiety Stress and Coping, 24(1), 107-120. doi: 10.1080/10615806.2010.481792

Gordis, E. B., Granger, D. A., Susman, E. J., \& Trickett, P. K. (2006). Asymmetry between salivary cortisol and alpha-amylase reactivity to stress: Relation to aggressive behavior in adolescents. Psychoneuroendocrinology, 31(8), 976-987. doi: 10.1016/j.psyneuen.2006. 05.010

Heaton, R. K. (1993). Wisconsin card sorting test manual. FL: Psychological Assessment Resources Odessa.

Heinz, A., Hermann, D., Smolka, M. N., Rieks, M., Gräf, K. J., Pöhlau, D., Kuhn, W., \& Bauer, M. (2003). Effects of acute psychological stress on adhesion molecules, interleukins and sex hormones: Implications for coronary heart disease. Psychopharmacology, 165(2), 111-117. doi: 10.1007/s00213-002-1244-6

Hermans, E. J., Putman, P., \& van-Honk, J. (2006). Testosterone administration reduces empathetic behavior: A facial mimicry study. Psychoneuroendocrinology, 31(7), 859-866. doi: 10.1016/j. psyneuen.2006.04.002

Herrero, N., Gadea, M., Rodríguez-Alarcón, G., Espert, R., \& Salvador, A. (2010). What happens when we get angry? Hormonal, cardiovascular and asymmetrical brain responses. Hormones and Behavior, 57(3), 276-283. doi: 10.1016/j.yhbeh.2009.12.008

Hines, D. A., \& Douglas, E. M. (2011). Alcohol and drug abuse in men who sustain intimate partner violence. Aggressive Behavior, 37, 1-16. doi: 10.1002/ab. 20418

Holtzworth-Munroe, A., \& Smutzler, N. (1996). Comparing the emotional reactions and behavioral intentions of violent and nonviolent husbands to aggressive, distressed, and other wife behaviors. Violence and Victims, 11(4), 319-339.

Holtzworth-Munroe, A., \& Stuart, G. L. (1994). Typologies of male batterers: three subtypes and the differences among them. Psychological Bulletin, 116(3), 476-497. doi: 10.1037/0033-2909.116.3.476

Kirschbaum, C., Kudielka, B. M., Gaab, J., Schommer, N. C., \& Hellhammer, D. H. (1999). Impact of gender, menstrual cycle phase and oral contraceptives on the activity of the hypothalamus-pituitaryadrenal axis. Psychosomatic Medicine, 61, 154-162. doi: 10.1016/ S0306-4530(02)00146-4

Kirschbaum, C., Pirke, K. M., \& Hellhammer, D. H. (1993). The "trier social stress test"-A tool for investigating psychobiology stress responses in a laboratory setting. Neuropsychobiology, 28, 76-81. doi: $10.1159 / 000119004$

Koenings, M., Young, L., Adolphs, R., Tranel, D., Cushman, F., Hauser, M., \& Damasio, A. (2007). Damage to the prefrontal cortex increases utilitarian moral judgments. Nature, 446, 908-911. doi: 10.1038/ nature 05631

Kornhuber, J., Erhard, G., Lenz, B., Kraus, K., Sperling, W., Bayerlein, K., Biermann, T., \& Stoessel, C. (2011). Low digit ratio 2D:4D in alcohol dependent patients. PLOS ONE, 6(4), e19332. doi: 10.1371/journal. pone. 0019332

Kudielka, B. M., Buske-Kirschbaum, A., Hellhammer, D. H., \& Kirschbaum, C. (2004). Differential heart rate reactivity and recovery after psychosocial stress (TSST) in healthy children, younger adults, 
and elderly adults: The impact of age and gender. International Journal of Behavioral Medicine, 11(2), 116-121. doi: 10.1207/s15327 558ijbm1102_8

Kudielka, B. M., von Känel, R., Preckel, D., Zgraggen, L., Mischler, K., \& Fischer, J. E. (2006). Exhaustion is associated with reduced habituation of free cortisol responses to repeated acute psychosocial stress. Biological Psychology, 72(2), 147-153. doi: 10.1016/j.biopsycho. 2005.09.001

Liening, S. H., \& Josephs, R. A. (2010). It is not just about testosterone: physiological mediators and moderators of testosterone's behavioral effects. Social and Personality Psychology Compass 4(11), 982-994. doi: 10.1111/j.1751-9004.2010.00316.x

Liening, S. H., Stanton, S. J., Saini, E. K., \& Schultheiss, O. C. (2010). Salivary testosterone, cortisol, and progesterone: Two-week stability, interhormone correlations, and effects of time of day, menstrual cycle, and oral contraceptive use on steroid hormone levels. Physiology and Behavior, 99, 8-16. doi: 10.1016/j.physbeh.2009.10.001

Lila, M., Oliver, A., Galiana, L., \& Gracia, E. (2013). Predicting success indicators of an intervention programme for convicted intimate-partner violence offenders: The contexto programme. European Journal of Psychology Applied to Legal Context, 5, 73-95.

Manning, J. T., Baron-Cohen, S., Wheelwright, S., \& Sanders, G. (2001). The 2nd to 4th digit ratio and autism. Developmental Medicine and Child Neurology, 43(3), 160-164.

Manning, J. T., \& Bundred, P. E. (2000). The ratio of 2nd to 4th digit length: A new predictor of disease predisposition? Medical Hypotheses, 54(5), 855-857. doi: 10.1054/mehy.1999.0000

Manning, J. T., Bundred, P. E., Newton, D. J., \& Flanagan, B. F. (2003). The second to fourth digit ratio and variation in the androgen receptor gene. Evolution and Human Behavior, 24(6), 399-405. doi: 10.1186/ 1477-7827-9-57

Manning, J. T., Scutt, D., Wilson, J., \& Lewis-Jones, D. I. (1998). The ratio of 2 nd to 4 th digit length: a predictor of sperm numbers and concentrations of testosterone, luteinizing hormone and oestrogen. Human Reproduction, 13(11), 3000-3004. doi: 10.1093/humrep/ 13.11.3000

Mestre, V., Frías, M. D., \& Samper, P. (2004). La medida de la empatía: análisis del Interpersonal Reactivity Index. Psichotema, 16(2), 255260.

Miguel-Tobal, J. J., Casado, M., Cano-Vindel, A., \& Spielberger, C. D. (2001). Adaptación española del Inventario de Expresión de Ira Estado-Rasgo STAXI-II. Madrid: Tea Ediciones.

Ministry of Interior. Technical General Secretary. (2010). Domestic violence. Batterers' Intervention Programs (BIP). Report 2010. Madrid: Penitentiary Issues.

Moriguchi, Y., Decety, J., Ohnishi, T., Maeda, M., Mori, T., Nemoto, K., Matsuda, H., \& Komaki, G. (2007). Empathy and judging other's pain: an fMRI study of alexithymia. Cerebral Cortex, 17(9), 2223-2234. doi: 10.1093/cercor/bhl130

Moya-Albiol, L. (2010). Psicobiología de la violencia. Madrid: Pirámide. Moya-Albiol, L., De Andrés-García, S., Sanchis-Calatayud, M. V., Sariñana-González, P., Ruiz-Robledillo, N., Romero-Martinez, A., \& González-Bono, E. (2012). Psychophysiological responses to cooperation: The role of outcome and gender. International Journal of Psychophysiology [Epub ahead of print].

Muller, M., Aleman, A., de Haan, E. H. F., \& van der Schouw, Y. T. (2005). Endogenous sex hormone levels and cognitive function in aging men. Neurology, 64(5), 866-871. doi: 10.1212/01.WNL.0000153072.540 68.E

Mullins-Nelson, J. L., Salekin, R. T., \& Leistico, A. M. R. (2006). Psychopathy, empathy, and perspective -taking ability in a community sample: Implications for the successful psychopathy concept. International Journal of Mental Health, 5(2), 133-149. doi: $10.1080 / 14999013.2006 .10471238$
Pinto, L. A., Sullivan, E. L., Ronsebaum, A., Wyngarden, N., Umhau, J. C., Miller, M. W., \& Taft, C. T. (2010). Biological correlates of intimate partner violence perpetration. Aggression and Violent Behavior, 15, 387-398. doi: 10.1016/j.avb.2010.07.001

Pope, H. G., Kouri, E. M., \& Hudson, J. I. (2000). Effects of supraphysiologic doses of testosterone on mood and aggression in normal men. Archives of General Psychiatry, 57, 133-140.

Popma, A., Vermeiren, R., Geluk, C. A. M. L., Rinne, T., van den Brink, W., Knol, D. L., Jansen, L. M. C., van Engeland, H., \& Doreleijers, T. A. H. (2007). Cortisol moderates the relationship between testosterone and aggression in delinquent male adolescents. Biological Psychiatry, 61(3), 405-411. doi: 10.1016/j.biopsych.2006.06.006

Pruessner, J. C., Kirschbaum, C., Meinlschmidt, G., \& Hellhammer, D. H., (2003). Two formulas for computation of the area under the curve represent measures of total hormone concentration versus timedependent change. Psychoneuroendocrinology, 29(4), 564-566. doi: 10.1016/S0306-4530(02)00108-7

Rogers, K., Dziobek, I., Hassenstab, J., Wolf, O. T., \& Convit, A. (2007). Who cares? Revisiting empathy in Asperger syndrome. Journal of Autism and Developmental Disorders, 37, 709-715. doi: 10.1007/ s10803-006-0197-8

Romero-Martínez, A., De Andrés-García, S., Sariñana-González, P., Sanchis-Calatayud, M. V., Roa-Natividad, J. M., González-Bono, E., \& Moya-Albiol, L. (2013). The 2D:4D ratio and its relationship with other androgenization parameters in parents of people with autism spectrum disorders. Annals of Psychology, 29(1), 264-271.

Romero-Martínez, A., González-Bono, E., Lila, M., \& Moya-Albiol, L. (2013). Testosterone/cortisol ratio in response to acute stress: A possible marker of risk for marital violence. Social Neuroscience, 8(3), 240-247. doi: 10.1080/17470919.2013.772072

Rowel, A. D., Bullock, P. R., Polkey, C. E., \& Morris, R. G. (2001). 'Theory of mind' impairments and their relationship to executive functioning following frontal lobe excisions. Brain, 124(3), 600-616. doi: 10.1093/ brain/124.3.600

Saunders, D. G. (1991). Procedures for adjusting self-reports of violence for social desirability bias. Journal of Interpersonal Violence, 6, 336-344.

Schoofs, D., \& Wolf, O. T. (2011). Are salivary gonadal steroid concentrations influenced by acute psychosocial stress? A study using the trier social stress test (TSST). International Journal of Psychophysiology, 80(1), 36-43. doi: 10.1016/j.ijpsycho.2011.01.008

Simons, J. S., Gaher, R. M., Jacobs, G. A., Meyer, D., \& Johnson-Jiménez, E. (2005). Associations between alcohol and PTSD symptoms among American Red Cross disaster relief workers responding to the 9/11/ 2001 attacks. The American Journal of Drug and Alcohol Abuse, 31, 347-364.

Smeets, T., Dziobeck, I., \& Wolf, O. T. (2009). Social cognition under stress: differential effects of stress induced cortisol elevations in healthy young men and women. Hormones and Behavior, 55(4), 507-513. doi: 10.1016/j.yhbeh.2009.01.011

Smith, M. J., Horan, W. P., Karpouzian, T. M., Abram, S. V., Cobia, D. J., \& Csernansky, J. G. (2012). Self-reported empathy deficits are uniquely associated with poor functioning in schizophrenia. Schizophrenia Research, 137(1-3), 196-202. doi: 10.1016/j.schres.2012.01.012

Soler, H., Vinayak, P., \& Quadagno, D. (2000). Biosocial aspects of domestic violence. Psychoneuroendocrinology, 25, 721-739. doi: S03 06-4530(00)00022-6

Spielberger, C. D., Gorusch, R. L., Lushene, R., Vagg, P. R., \& Jacobs, G. A. (1983). Manual for the state-trait anxiety inventory. Palo Alto, CA: Consulting Psychologists Press.

Stalder, T., Evans, P., Hucklebridge, F., \& Clow, A. (2011). Associations between the cortisol awakening response and heart rate variability. Psychoneuroendocrinology, 36, 454-462. doi: 10.1016/j.psyneuen. 2010.07.020 
Steele, C., \& Josephs, R. (1990). Alcohol myopia: Its prized and dangerous effects. The American Psychologist, 45, 921-933. doi: 10.1037/0003066X.45.8.921

Teichner, G., Golden, C. J., Van Hasselt, V. B., \& Peterson, A. (2001). Assessment of cognitive functioning in men who batter. The International Journal of Neuroscience, 111(3), 241-253.

Terburg, D., Morgan, B., \& van-Honk, J. (2009). The testosterone-cortisol ratio: A hormonal marker for proneness to social aggression. International Journal of Law and Psychiatry, 32(4), 216223.

Tirapu-Ustárroz, J., Pérez-Sayes, G., Erekatxo-Bilbao, M., \& PelegrínValero, C. (2007). What is theory of mind? Revista de Neurologia, 44 (8), 479-489. van Honk, J., \& Schutter, D. J. (2007). Testosterone reduces conscious detection of signals serving social correction: Implications for antisocial behavior. Psychological Science, 18(8), 663-667.

van Honk, J., Schutter, D. J., Bos, P. A., Kruijt, A. W., Lentjes, E. G., \& Baron-Cohen, S. (2011). Testosterone administration impairs cognitive empathy in women depending on second-to-fourth digit ratio. Proceedings of the National Academy of Science United States of America, 108(8), 3448-3452. doi: 10.1073/pnas.1011891108

WHO. (2011). Multi-country study on women's health and domestic violence progress report. WHO/WHD, Geneva.

Wolf, O. T. (2011). Immediate recall influences the effects of pre-encoding stress on emotional episodic long-term memory consolidation in healthy young men. Stress, 8, 1-9. 